\title{
Investigation of the Robust Absolute Stability of the Tunnel Kiln Control System with Delay
}

\author{
TSELIGOROV N.A., CHUBUKIN A.V., TSELIGOROVA E.N. \\ Department of Computing Systems and Information Security \\ Don State Technical University \\ 1, Gagarin square, Rostov-on-Don, 344000 \\ RUSSIA
}

\begin{abstract}
The paper considers the system of automatic control of the tunnel kiln temperature conditions. The investigation of a delay influence on the transition process has been carried on. The transfer function of the object under control with interval coefficients taking into account possible effects of the parametric uncertainty has been obtained. A graphical method of representing the obtained results in the form of displaying the modified amplitude-phase characteristics on a complex plane has been applied which obviously demonstrates a robust absolute stability of the system under investigation. The simulation performed in the Matlab environment has proved the correctness of the results obtained.
\end{abstract}

Key-Words: - stability, robust absolute stability, parametric uncertainty, interval polynomial

Received: September 26, 2020. Revised: February 22, 2021. Accepted: March 5, 2021. Published: March 12, 2021.

\section{Introduction}

Tunnel kilns are intended for bricks firing with the purpose of giving them water-resistant, mechanical strength properties and increasing their mechanical stability to temperature fluctuations. This kiln is structurally designed in the form of a tunnel where a batch of raw bricks placed on trolleys enters from one side of the tunnel and, moving to the output end of the tunnel, takes out the finished batch of bricks. During the whole this cycle the bricks being fired go through the whole cycle of temperature treatment, beginning from the preliminary drying $\left(\sim 200^{\circ} \mathrm{C}\right)$ and finishing with holding a batch of bricks at the limiting values of temperature conditions $\left(920^{\circ} \mathrm{C}\right)$, after which the temperature conditions begin to decrease. This cycle usually takes from 5 to 50 hours [1]. Liquid or solid fuel can be used but natural gas is most preferred. In order to get quality product, it is necessary to provide accurate adjustment of gas supply, as well as supply of air as ensuring both firing and cooling of the finished product. Application of automation for the processes of heating, firing and also cooling of bricks makes it possible to provide optimal technical and economic indicators of the tunnel kiln operation

\section{Problem Formulation}

To maintain the required temperature of firing the analogue automatic control systems (ACS) are most often used for regulating temperature of firing, which is usually in the range from 920 to 980 degrees. The tunnel belt kiln as a controlled object has interval- uncertain parameters, which should be taken into account while carrying out the synthesis of the controller. To improve stability of the controller parameters and to achieve interval stability it is reasonable to apply digital implementation of the control system. The mathematical model, according to which schematic, functional, and structural diagrams for brick firing temperature control were worked out, is presented in [2]. However, the paper does not contain detailed numerical data, and, in addition, there is not a simulation to confirm the suggested approach. In paper [3] a mathematical model of ACS for the temperature in the tunnel kiln of a conveyor type is presented, the parameters of which were determined, simulation of the temperature automatic control system in Matlab environment was carried out without taking into consideration interval character of its parameters.

Moreover, the conducted investigations do not touch upon such important field as influence of endogenous and exogenous uncertainties on the robust stability of the given system. In recent times, this problem is paid much attention [4-6]. The robust stability of the systems with delay was investigated in papers $[7,8]$. The robust stability of the control systems with parametric uncertainty was considered in papers $[9,10]$. Adaptive systems were considered in papers [11-14]. Much attention is also paid to displaying the obtained results [15-17]. So, 
in $[18,19]$ the results obtained are presented in an analytical form. In recent times, the attention is paid to displaying the investigation results in the form of the corresponding graphic images [20-24].

\section{Problem Solution}

To solve the problem under consideration, it is necessary, first of all, to adopt the method of accounting in a mathematical model of a kiln with transport delay, then, in a sequential order, perform the simulation of the system for brick firing temperature control as analog and then as a discrete one. At the final stage, it is necessary to carry on the investigation of the temperature control system taking into account the main uncertainties being available in the system, i.e., investigate the control system with interval coefficients of the transfer function.

The tunnel kiln is an object of control, the controlled value of which is the temperature of firing, and the external disturbing effect $f$ is a combination of various factors: the initial moisture and temperature of bricks being fired, changes in temperature and humidity of the atmospheric air. When investigating the system, it is possible to be confined to the account of influence of the initial brick moisture on the object of control considering it as the main disturbing effect.

\subsection{Choice of an Approximation Method for Transport Delay}

Automatic control systems (ACS) for the objects with delay constitute a vast class of industrial control systems that reflects the constant interest in them during decades. Their special feature consists in the availability of a delay link described by the transfer function $e^{-p T_{3}}$, which does not allow to use classical methods of synthesis and investigation of control systems. To remove obstacles, the approximation procedure of the $e^{-p T_{3}}$ function is usually applied with a suitable fractional rational expression which makes it possible to use standard methods for calculating ACS [25].
In spite of the obviousness and simplicity of this way, it has some negative aspects. Firstly, in the initial equation of the ACS synthesis where there is a desired transfer function of a reference system, there appears an error component, determined by the transition from accurate presentation of the delay link to the approximate one. Secondly, at the stage of assessing the accuracy of the system synthesis, they usually strive to get its transient characteristic which makes it possible to find direct indicators of quality. However, here we have to approximate the delay link, as otherwise the problem, with the exception of the simplest cases, appears to be unsolvable. In the third place, for some systems it is necessary to determine time-response characteristics of the ACS with increased accuracy at small or large values of time, and this requires the appropriate tool while approximating the delay link.

At present, the two basic methods of approximating the delay link are applied, they are distinguished by the simplicity of calculations: expansion of the transfer function $e^{-p T_{3}}$ in a Taylor series and representation of this function in the form of a Pade fraction [25]. Both methods basically use Taylor power series; comparing the presented expressions, it can be noted that the approximation capabilities of the second alternative must be higher, since it has a larger number of variable coefficients.

Let us present the transfer functions of the links of the kiln temperature control system which make it possible to calculate the transfer function of an open-loop system, on the basis of which a dynamic calculation of the controller can be then carried out.

The transfer function of the tunnel kiln for the control action has the form

$$
W_{y n p}(p)=\frac{k_{y n p} e^{-p T_{3}}}{T_{1} T_{2} p^{2}+\left(T_{1}+T_{2}\right) p^{2}+1},
$$

where $T_{1}$ is the basic time constant of the kiln, equal to $5,2 \mathrm{~s}$;

$T_{2}$ is time constant of the controlling and actuating device, equal to $0,64 \mathrm{~s}$;

$T_{3}$ is time constant of the transportation delay link, equal to $1,8 \mathrm{~s}$. 
The transfer function approximating the function of transport delay by the way of expanding in Pade series has the form:

$$
W_{\text {заn }}(p)=\frac{1-T_{3} p}{T_{3} p+1} .
$$

The transfer function of the approximated controlled object will be written in the form:

$$
W_{y n p}(p)=\frac{-0,23438(p-1,111)}{(p+1,562)(p+1,111)(p+0,1923)} .
$$

To perform the simulation of the tunnel kiln, let us develop a structural model of the controlled object presented in fig. 1

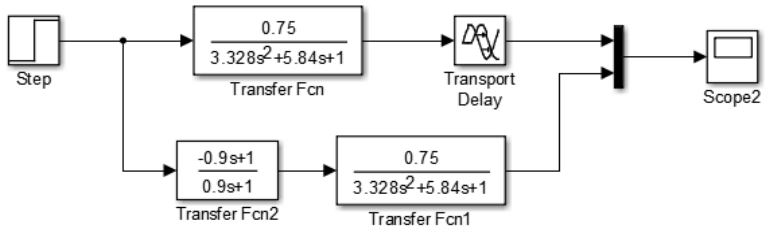

Fig.1. The structural model of the object with transport delay and the approximated delay function

To assess the accuracy of approximation a structural model of the controlled object was developed (fig.1), with the help of which the transition functions, shown in fig.2, for the indicated variants of the model were constructed.

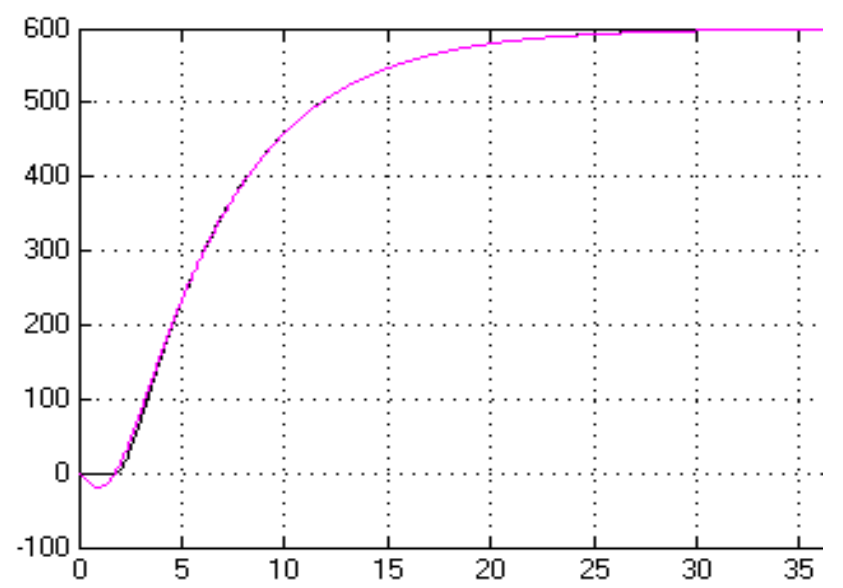

Fig.2. Transition functions of the controlled object

\subsection{Investigation of the System Discrete Model}

Let us study the temperature control system of the tunnel kiln as a discrete model of the automatic control system depending on endogenous and exogenous uncertainties. For this purpose, we use the transfer function of the kiln for the control action taking into account the adopted approximation of the transport delay (2). Since it is supposed to implement a digital PID temperature controller, then it is necessary to convert the transfer function (2) into a digital form. In order to do that, we will use the MATLAB-Control System Toolbox application program package, as well as for all subsequent calculations. Let us assume the discreteness period being equal to $0.1 \mathrm{~s}$ and calculate a discrete transfer function of the kiln with consideration of the zero-order extrapolator. The discrete transfer function of the controlled object in terms of zpk has the form:

$$
W_{\text {ynp }}(z)=\frac{-0.0010254(z+0.8759)(z-1.118)}{(z-0.981)(z-0.8948)(z-0.8553)} .
$$

When carrying out the synthesis of the controller it is necessary to take into account obtaining robustness of the kiln temperature control system under the conditions of interval changes in its parameters. As it is known, a log magnitude maximum value of a closed-loop control system can serve as an indirect sign of robustness, therefore, the maximum reserves in modulus and phase of an open-loop system [18]. Since the controller must be digital, we choose it of standard PIDF type and calculate its parameters with the help of the pidtool program.

As a result of calculations, the following controller parameters have been obtained: $k_{p}=2,824$ is a proportional gain factor, $k i=0,4258$ is an integral gain factor, $k_{d}=3,9$ is a differential gain factor, $T_{f}=0,0738 \mathrm{~s}$ is a filter time constant. In this case, the discrete transfer function of the PID controller is written in the following form:

$$
W_{\text {pez }}(z)=\frac{18.84 z^{2}-35.347 z+16.53}{z^{2}-1.192 z+0.192} .
$$

To check the correctness of the performed synthesis of the controller, we will draw up a structural diagram of the closed-loop system for the kiln temperature control (fig. 3), with the help of which we will investigate its dynamic properties. 


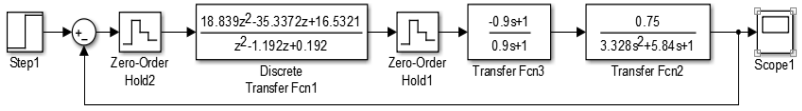

Fig.3. Structural diagram of ACS for the kiln temperature

The transient function in terms of control action is shown in fig. 4. Its analysis indicates that the dynamic parameters, claimed during the synthesis, have been carried out.

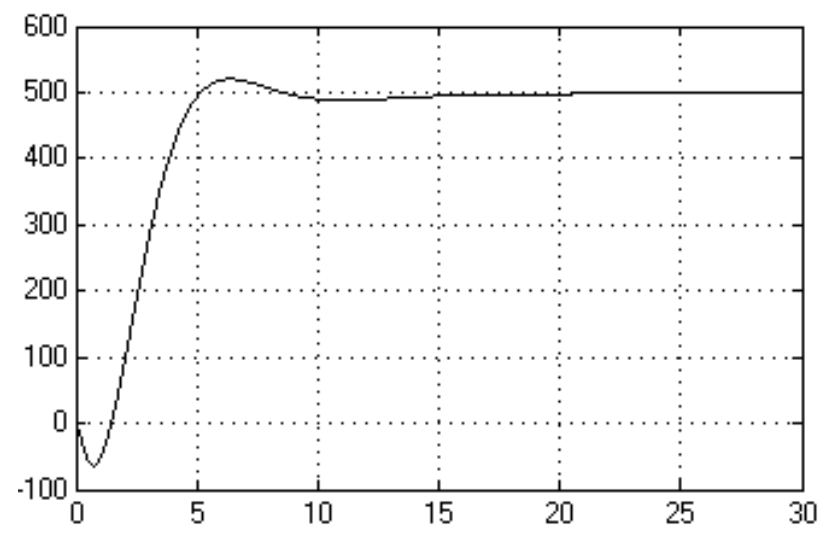

Fig.4. Transition function of the closed-loop ACS in terms of control action

It is expedient to perform the preliminary estimation of the system robustness according to the estimation of the maximum value of the amplitudephase-frequency characteristic of the closed-loop system which is presented in fig. 5 .

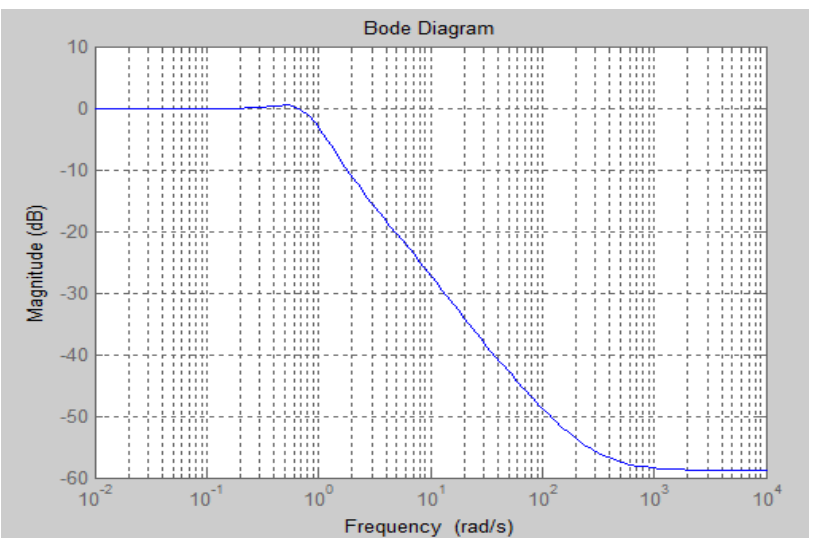

Fig.5. Amplitude-phase-frequency characteristic of the closed-loop system for the kiln control

Thus, we can see in fig. 5 the absence of amplitude peaks in a closed-loop system above the frequency axis, which is illustrative of a change in parameters of the system within wide limits while maintaining its stability.

\subsection{Investigation of robust absolute stability of ACS for the tunnel kiln}

Let us run a check of the robust absolute stability of this system applying graphical approach [16] based on the construction of modified amplitudephase characteristics for the transfer function (3). The coefficients of the numerator and denominator of this transfer function have a deviation from the reference values within the limits of $\pm 10 \%$.

The transfer function of the system with interval parameters after the w-transformation has the following form

$$
\begin{gathered}
W(w)=\frac{(0,00103 . .0,00125) w^{5}+(0,294 . .0,356) w^{4}-(7,559 . .6,185) w^{3}-}{(0,9 . .1,1) w^{5}+(15,048 . .18,392) w^{4}+(30,726 . .37,554) w^{3}+} \\
\frac{-(1,936 . .1,584) w^{2}+(7,763 . .9,487) w+(1,349 . .1,647)}{+(26,0,82 . .31,878) w^{2}+(11,826 . .14,454) w+(1,349.1,647)}
\end{gathered}
$$

The plotted diagram of the modified amplitudephase characteristics for the transfer function with interval coefficients is presented in fig. 6 .

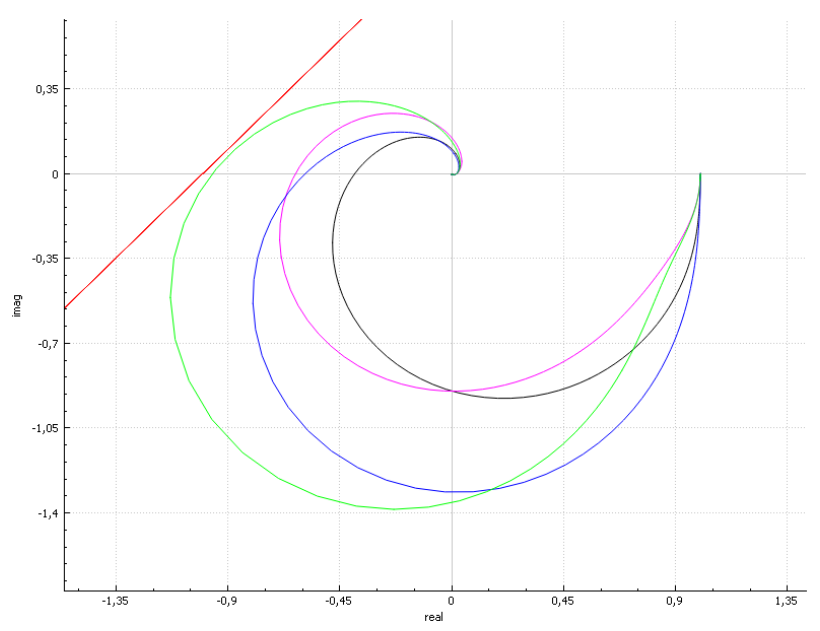

Fig. 6. The diagram of the modified amplitudephase characteristics

In the presented figure we can see that all the modified amplitude-phase characteristics are located strictly to the right of the Popov line and this indicates the robust absolute stability of the discrete system under investigation. 


\section{Conclusion}

The suggested approach to the implementation of the tunnel kiln temperature control system has shown that in spite of the presence of the delay link in the system under investigation, the possibility of applying PID controller has been demonstrated which has ensured the robust absolute stability of the investigated discrete system with $\pm 10 \%$ spread of its parameters.

\section{References:}

[1] Brick equipment/ http://chinabrick.ru/2013/02/tunnelnaya-pech/

[2] Lappo I. A. System for automatic temperature control of the brick kiln/ http://rep.bntu.by/handle/data/30646

[3] Ilyushin Yu. V. Automatic temperature control system for a tunnel oven of conveyor type/ www.gramota.net/materials/1/2012/4/29.html

[4] Bhattacharyya S.P. Robust control under parametric uncertainty, An overview and recent results, Annu. Rev. Control, 2017, pp. 45-77.

[5] Chen X., Chen M., Shen J. A novel approach to $1_{1}$-induced controller synthesis for positive systems with interval uncertainties, Journal of The Franklin Institute, Vol. 354(8), 2017, pp. 3364-3377.

[6] Elloumi W., Mendi D., Chaabane M. Robust Controlled Positive Delayed Systems with Interval Parameter Uncertainties: A Delay Uniform Decomposition Approach, Int. J. Appl. Math. Comput. Sci, Vol. 28, No. 3, 2018, pp. 441-450.

[7] De la Sen M. Robust stability analysis and dynamic gain-scheduled controller design for point time-delay systems with parametrical uncertainties, Communications in Non linear Science and Numerical Simulation, Vol. 13, No. 6, 2008, pp. 1131-1156.

[8] Wang Z. H., Hu H. Y. Robust Stability of TimeDelay Systems with Uncertain Parameters, Proceedings of the IUTAM Symposium, 2006, pp. 363-372.

[9] Fuh C. C., Tuhg P. C. Robust stability bounds for Lur'e systems with parametric uncertainty, Journal of Marine Science and Technology, Vol. 7, No. 2, 1999, pp. 73-78.

[10] Matušů R., Şenol B., Pekař L. Value-Set-Based Approach to Robust Stability Analysis for Ellipsoidal Families of Fractional-Order Polynomials with Complicated Uncertainty
Structure, Applied Sciences, Vol. 9, No. 24, 2019, 18 p.

[11] Wang R., Li J. Adaptive neural control for a class of perturbed time-delay nonlinear systems, Proceedings of the 7th International Conference on Computational Intelligence and Security (CIS '11), 2011, pp. 358-361.

[12] Yang B-J., Calise A-J. Adaptive control of a class of nonaffine systems using neural networks, IEEE Transactions on Neural Networks, Vol. 18(4), 2007, pp.1149-1159.

[13] Wang R., Gao D., Li J. Robust adaptive sliding mode control design for a class of uncertain neutral systems with distributed delays, Proceedings of the 7th International Conference on Computational Intelligence and Security (CIS '11), 2011, pp.1539-1541.

[14] Wang R., Li J., Zhang S., Gao D., Sun H. Robust Adaptive Control for a Class of Uncertain Nonlinear Systems with TimeVarying Delay, Scientific World Journal, 2013, $8 \mathrm{p}$.

[15] Prokop R., Volkova N., and Prokopova Z. Tracking and disturbance attenuation for unstable systems: Algebraic approach, Recent Researches in Automatic Control - 13th WSEAS International Conference on Automatic Control, 2011, pp. 57-62.

[16] Tseligorov N.A., Tseligorova E. N., and Mafura G.M. Using Information Technology for Computer Modeling of Nonlinear Monotonous Impulse Control System with Uncertainties, Proceeding of the Computer Modeling and Simulation, 2014, pp. 75-80.

[17] Matušů R., Şenol B. Application of Value Set Concept to Ellipsoidal Polynomial Families with Multilinear Uncertainty Structure. In Computational Statistics and Mathematical Modeling Methods in Intelligent Systems, Proceedings of 3rd Computational Methods in Systems and Software, Vol. 2, 2019, pp. 81-89.

[18] Phillips C. L., Harbor R. D. Feedback Control Systems, 4th Edition, Publisher: Prentice Hall, 2000.

[19] Haddad W.M., Collins Jr.E.G., Bernstein D. S. Robust stability analysis using the small gain, circle positivity, and Popov theorems: a comparative study, IEEE Trans. Control Syst. Techn, Vol.1, 1993, pp. 290-293.

[20] Matušů R. Robust Stability Analysis of Discrete-Time Systems with Parametric Uncertainty: A Graphical Approach, International journal of mathematical models 
and methods in applied sciences, Vol. 8, 2014, pp. 95-102.

[21] Matušů R., and Prokop R. Graphical Analysis of Robust Stability for Polynomials with Uncertain Coefficients in Matlab Environment, Proceeding of the 16th WSEAS International Conference on Systems, 2012, pp. 242-247.

[22] Matušů R., and Prokop R. Graphical Approach to Robust Stability Analysis for Discrete-Time Interval Polynomials, Proceeding of the 15th WSEAS International Conference on Mathematical and Computational Methods in Science and Engineering, 2013, pp. 34-37.

[23] Tseligorov N.A., Mafura G.M. and Tseligorova E.N. Robust absolute stability analysis of a temperature control system for an enclosed space, Proceedings of the 13th International Asian School-Seminar in the framework of the international multiconference, 2017, pp. 356- 359.

[24] Tseligorov N.A., Chubukin A.V. and Ozersky A.I. Improving the efficiency of dynamic modes of electro-hydraulic drive operation, Proceedings of the 6th International Conference on Industrial Engineering (ICIE 2020), 2020, p.p. 32-36.

[25] Gani, M.M., Islam, M.S. and Ullah, M.A. Optimal PID tuning for controlling the temperature of electric furnace by genetic algorithm. SN Appl. Sci., 2019, Vol. 1, 880 p.

\section{Contribution of individual authors to the creation of a scientific article (ghostwriting policy)}

Author Contributions:

Tseligorov N.A. conducted investigation of the tunnel kiln control system for robust stability. Chubukin A.V. investigated this control system with the account of the transport delay. Tseligorova E.N. performed simulation.

\section{Creative Commons Attribution License 4.0 (Attribution 4.0 International, CC BY 4.0)}

This article is published under the terms of the Creative Commons Attribution License 4.0

https://creativecommons.org/licenses/by/4.0/deed.en US 